\title{
Epidemiology, public health and the problem of personality disorder*
}

JEREMY COID

\author{
Background The public health \\ problem-solving paradigm is a \\ comprehensive method not previously \\ applied to preventive interventions for \\ personality disorder.
}

Aims To present an overview for clinical psychiatrists.

\begin{abstract}
Method Review of epidemiological research into DSM-IV Axis II disorders and application to the paradigm.
\end{abstract}

Results Personality disorder affects a substantial proportion of the population. Burdens on health care, social and criminal justice agencies have yet to be accurately quantified. Debates continue over case definition, but there is increasing information on prevalence using 'broad' definitions and aetiology. A conceptual framework, based on development, suggests preventive interventions should be targeted in childhood. The public health approach also requires monitoring of risk factors operating at the population level.

\section{Conclusions Services in England and Wales for persons with personality disorder are currently inadequate. The problem-solving paradigm suggests new preventive interventions. Psychiatrists should renegotiate their relationship with policy-makers and reconsider their preventive role.}

\section{Declaration of interest None.}

* Paper presented at the second conference of the British and Irish Group for the Study of Personality Disorders (BIGSPD), University of Leicester, UK, 3I January to 3 February 200I.
The purpose of this review is to re-examine the epidemiology of personality disorder and to develop a set of concepts for addressing the problem using the public health problem-solving paradigm. The paradigm is described by Guyer (1998) as including the following steps:

(a) defining the problem;

(b) measuring the magnitude of the problem;

(c) developing a conceptual framework for the key determinants of the problem, including biological, epidemiological, socio-cultural, economic and political determinants;

(d) identifying and developing intervention and prevention strategies;

(e) setting priorities among strategies and recommending policies;

(f) implementing programmes and evaluating them.

\section{METHOD}

Computerised Medline, PsycINFO and International Bibliography of the Social Sciences searches were performed from January 1990 to December 2001 using the terms PERSONALITY DISORDER, AXIS II DISORDER, PUBLIC HEALTH, EPIDEMIOLOGY. In addition, a series of official reports and book chapter reviews of the area were cross-referenced. The aim was to review the major findings of the epidemiological studies of personality disorder together with their public health implications. This was not an inclusive review, and the choice of articles reflects the author's qualitative assessment of current themes of importance in this area of research.

\section{RESULTS}

\section{Epidemiology}

There have been several previous reviews of the epidemiology of personality disorder, but these have not considered a public health approach. Epidemiology is often considered to be the basic science of public health (Brownson, 1998). The most widely accepted definition is 'the study of the distribution and determinants of healthrelated states or events in specified populations, and the application of this study to control of health problems' (Last, 1995). However, a definition relevant to public health practice describes epidemiology as the study of the health of human populations. The functions of epidemiology are:

(a) to discover the agent, host and environmental factors which affect health in order to provide a scientific basis for the prevention of disease and injury and the promotion of health;

(b) to determine the relative importance of causes of illness, disability and death, in order to establish priorities for research and action;

(c) to identify those sections of the population which are at greatest risk from specific causes of ill health, in order that the indicated action may be directed appropriately;

(d) to evaluate the effectiveness of health programmes and services in improving the health of the population (Terris, 1992).

Each of these four functions aims to improve the overall health of the population. They can be reformulated as questions for the future epidemiological study of personality disorder (Appendix).

\section{Future studies}

If more were known about aetiological risk factors for personality disorders and associated factors leading to disability and mortality, then key priorities could be established for future research and action. For example, clinicians may incorrectly believe that the conditions they encounter most frequently result in the heaviest burden of care. Borderline personality disorder is the most frequently encountered personality disorder in in-patient settings and receives considerable research interest. But persons with borderline personality disorder are characterised by strong tendencies to seek psychiatric help. In contrast, individuals with antisocial personality disorder may place greater burdens on society and the criminal justice system. Systematic studies of burden of care and costs to 
society posed by different categories of personality disorder are urgently required, especially when these are displaced onto a range of organisations outside the health care system.

\section{New services}

Little is known about the geographical distribution of the disorders of personality or which sections of the population are at greatest risk. Although several targeted or 'high-risk' (Rose, 1992) health care interventions exist, or are currently under development in the UK, it must be questioned whether these are based on evaluation of need, whether they are appropriately located and whether expediency could have determined their development. It is generally assumed that new services will automatically undergo future evaluation. However, certain services for individuals with personality disorder have remained unchanged for years, without systematic evaluation of either effectiveness or value for money (Dolan \& Coid, 1993).

\section{Public health methods}

Clinicians who treat patients with personality disorder might argue that it is premature to take a public health view of the problem while epidemiological information remains limited. However, public health has the advantage of linking the biological basis of health and disease with social and political processes of society. Solving problems in public health is fundamentally different from medical diagnosis and the treatment of personality disorder and it requires a broader conceptual framework. For example, a child psychiatrist may be unimpressed that a boy with conduct disorder has been treated successfully for fire-setting behaviour, if the original goal was to bring about a generalised improvement of a range of disordered behaviours, and where associated truanting, fighting, stealing, running away from home and substance misuse continue. But a criminologist or epidemiologist interested in fire-setting at the population level might take a different view. A significant proportion of malicious fire-setting remains uncleared by the police in the UK and is believed to be perpetrated by youths, often while truanting. In certain inner-city areas, extensive damage and accompanying deterioration of the urban environment have resulted. If an intervention were applied which resulted in even a small percentage drop in fire-setting behaviour in a population of young persons, this would be considered a major public health achievement, as well as successful crime prevention.

Rose (1992) divided preventive interventions into 'high-risk' strategies, which are targeted at individuals identified as at high risk, and 'population' strategies, aimed at bringing about overall population change. Current interventions for personality disorder do not extend beyond the first category. A public health perspective requires a broader view which takes into account the determinants of these conditions, organisation of available health services, and political issues.

\section{Problem definition (beyond ICD-IO and DSM-IV)}

Defining the problem may be the single most important step in public health problem-solving (Guyer, 1998). For personality disorder, it remains the biggest problem. Despite attempts to bring ICD10 (World Health Organization, 1992) and DSM-IV (American Psychiatric Association, 1994) personality disorder categories closer, this has not been achieved (most researchers use DSM-IV). There is little consensus regarding research diagnostic instruments, whether interviews or self-report methods produce superior data (Loranger, 1992), when patients should be evaluated, or whether subject or informant data are more accurate (Zimmerman, 1994). Although self-report instruments are criticised for producing false-positive diagnoses, there is no gold standard for comparing instruments. Even structured clinical interviews show divergent results when compared, and where one instrument cannot simply be substituted for another (Clark et al, 1997). Major problems remain in test-retest reliability.

Despite the definition of personality disorder as an enduring pattern of inner experience and behaviour which is inflexible, pervasive, stable and of long duration, research increasingly reveals that these conditions show major fluctuations. For example, early findings from a US multisite study of patients with borderline, avoidant, schizotypal and obsessive-compulsive personality disorder found that $40 \%, 30 \%$, $32 \%$ and $31 \%$, respectively, no longer met criteria at 6-month follow-up (Shea et al, 1999). In contrast, measures of personality using the 5-factor model Neuroticism, Extraversion and Other - Personality
Inventory - Revised (NEO-PI-R) remained stable (Morey et al, 1999). Personality may show stability over time but personality disorder does not, thereby challenging its own definition.

Debates continue over whether to include categorical or dimensional classifications, the latter appealing to those whose theoretical approach is influenced by psychological trait theory, the former to those with a medical training. The debate emphasises important public health considerations of who sets the definitions of personality disorder and how they are set. Categories in ICD-10 and DSM-IV were finally arrived at following complex committee negotiations between experts. The origins of individual categories, including psychoanalysis (narcissistic, borderline personality disorder), empirical longitudinal research (antisocial personality disorder), clinical observations by influential early 20th century German clinicians (dependent, obsessive-compulsive, paranoid disorders) can be obscured by subsequent changes of clinical opinion, new research and negotiations which precede new editions of the glossaries.

Psychiatrists are prisoners of the diagnostic glossaries of their time. But despite shortcomings in case definition, it has been argued that current categories are good enough and should be tested in epidemiologically representative samples (Dolan \& Coid, 1993). Public health surveillance strategies find broad case definitions acceptable in the early stages and in the absence of laboratory data. When a deeper understanding of the disease process emerges, a more refined definition can be substituted (Thacker \& Stroup, 1998). Meanwhile, it is important not to be constrained by the relative narrowness of current definitions, expanding case definition to include associated psychiatric morbidity, social problems and mortality, as exemplified above by conduct disorder and fire-setting. This is illustrated by the unresolved problem of measuring severity of personality disorder using current diagnostic constructs, where it is necessary to use additional external measures such as burden on health care services, financial costs to society over the lifetime, criminality and the effect of behaviour on others.

\section{Measuring the magnitude of the problem}

Initial measurement usually involves incidence and prevalence, but is intended to 
go beyond these to define the populations at risk and adopt indicators that correspond to the problem definition. However, this latter stage has not been reached in epidemiological personality disorder research, which is largely confined to population surveys. Jenkins (2001) has argued that large-scale surveys can address deficiencies in problem-solving. First, effective policy needs to be based on epidemiology and social and economic causes and consequences of psychiatric morbidity. Second, representative information on a defined geographical area can document the use of existing services, estimate unmet needs and identify services that are required. Third, valid information on prevalence and associated risk factors allows aetiological hypotheses to be generated and tested, and models developed for prevention. Fourth, by repeating community surveys it is possible to monitor trends and the health of the population.

Table 1 demonstrates the prevalence of DSM-IV Axis II categories in surveys using interviews with subjects (Lyons, 1995; Reich \& de Girolamo, 1997; Moran, 1999; Royal College of Psychiatrists, 1999; Singleton et al, 2001; Torgersen et al, 2001). The main findings for individual categories are as follows.

\section{Paranoid}

This category is more common in males and persons of lower social class, and more common among relatives of probands with schizophrenia than among relatives of controls. In forensic samples, it is frequently comorbid with antisocial

Table I Prevalence of personality disorder in community surveys

\begin{tabular}{lc}
\hline Personality disorder & $\begin{array}{c}\% \text { of } \\
\text { population }\end{array}$ \\
\hline Antisocial & $0.6-3.0$ \\
Borderline & $0.7-2.0$ \\
Narcissistic & $0.4-0.8$ \\
Histrionic & 2.1 \\
Paranoid & $0.7-2.4$ \\
Schizoid & $0.4-1.7$ \\
Schizotypal & $0.1-5.6$ \\
Avoidant & $0.8-5.0$ \\
Dependent & $1.0-1.7$ \\
Compulsive & $1.7-2.2$ \\
Any & $4.4-13.0$ \\
\hline
\end{tabular}

personality disorder and associated with violent crime.

\section{Schizoid}

Schizoid personality disorder is uncommon in clinical settings but is more prevalent in offender populations, where it is more common in males (Coid, 1992; Singleton et al, 1998). Studies of comorbidity demonstrate association with schizotypal personality disorder. However, it has been suggested that this category might be better classified as a neurodevelopmental disorder than a personality disorder (Coid, 1999), possibly within the autistic spectrum (Woolff \& Chick, 1980; Wing, 1981).

\section{Schizotypal}

Schizotypal personality disorder is common in relatives of probands with schizophrenia (15\%) (Baron et al, 1985) and studies of comorbidity have demonstrated associations with schizophrenia. However, the future of this personality disorder category is uncertain as it is now included with schizophrenia in ICD-10.

\section{Avoidant}

In clinical samples, avoidant personality disorder is comorbid with dependent personality disorder and phobic disorder, specifically social phobia, which has similar clinical features (Herbert et al, 1992; Holt et al, 1992; Turner et al, 1993), and where the separation between the Axis I and Axis II disorders may be questionable.

\section{Dependent}

Dependent personality disorder is comorbid with borderline personality disorder in certain studies, but has been described as lacking a clear delineation from certain personality disorder categories such as avoidant. The aetiology is thought to be the outcome of early social processes within the family environment, although in a forensic sample it was associated with neuropsychiatric risk factors (Coid, 1999).

\section{Obsessive-compulsive}

Obsessive-compulsive disorder has been described as a 'high-functioning' category (Kernberg, 1984) and is more common in white, male, highly educated, married and employed individuals. It is comorbid with anxiety disorders in some studies.

\section{Narcissistic}

Surveys tend to find a low prevalence of this condition. This Axis II construct is derived from psychodynamic theory (Kohut, 1971; Kernberg, 1975) but has not converted well to the DSM-IV format. It is diagnosed more frequently in males and is more common in forensic samples, where it is comorbid with antisocial personality disorder.

\section{Histrionic}

Earlier research in clinical populations suggested that histrionic personality disorder was more common in women. More recent studies indicate that the gender ratio is similar. It is more common in divorced and separated persons, associated with parasuicide, and associated in women with unexplained medical conditions and in men with substance misuse.

\section{Borderline}

Borderline personality disorder is more prevalent in younger age groups (19-34 years), females (not all surveys) and Whites (not all surveys); is associated with poor work history and single marital status; and is more common in urban areas. It is comorbid with substance misuse, phobia and anxiety disorder, and has a $9 \%$ suicide rate (Paris et al, 1987, 1989; Stone, 1990). In forensic samples it is comorbid with antisocial personality disorder. Most epidemiological studies demonstrate lifetime comorbid depression, and a raised prevalence of depression has been observed in the relatives of borderline probands (Riso et al, 2000). It has been argued that the association with depressive illness is weak and non-specific (Gunderson \& Phillips, 1991); it has also been argued that borderline personality disorder is an affective disorder (Coid, 1993). The aetiology of borderline personality disorder is thought to include a combination of neuropsychiatric, genetic and early adverse factors in the social environment. Longitudinal studies indicate that borderline personality disorder is most severe in the mid-20s, with improvement noted in the late 30s (McGlashan, 1986; Paris, 1988; Paris et al, 1989; Stone, 1990). At 15-year follow-up, most subjects with borderline personality disorder no longer meet the criteria for the condition, although a subgroup has a poor long-term outcome. Patients with borderline personality disorder are 
typically treatment-seeking and high users of mental health services.

\section{Antisocial}

Antisocial personality disorder has a prevalence of $2-3 \%$ in most Westernised societies and is 4-5 times more common in men than in women. In the USA it has been found to be no higher in Blacks than in Whites. However, two recent European surveys indicate a lower prevalence of $0.7 \%$ for individuals aged $18-65$ years in Oslo, Norway (Torgersen et al, 2001), and $0.6 \%$ for individuals aged $16-74$ years in England, Scotland and Wales (Singleton et al, 2001). The highest prevalence is in the 25- to 44-year age band. Antisocial personality disorder is associated with school drop-out, homelessness and raised mortality in early adulthood. The prevalence is raised in inner-city populations and lower in rural areas. It is highly comorbid with substance misuse. The symptoms of antisocial personality disorder diminish in middle age, but $20 \%$ still meet the criteria at 45 years of age.

\section{Key determinants and conceptual frameworks}

It is important to develop conceptual frameworks which can organise the disparate range of risk factors for personality disorder into a set of domains which are linked logically to outcome and which will become the organisational principle for future intervention strategies. Table 2 describes a longitudinal (or developmental) framework for high-risk offenders with personality disorder. The model indicates progression from one stage to another, assuming increasing severity of both personality disorder and associated antisocial behaviour over time. Although the table suggests a highly adverse outcome by midlife, most individuals demonstrating antisocial behaviour and experiencing these risk factors will drop out before reaching this end-point. Progression from one stage to another is dependent on a theoretical framework based on a balance between 'risk' and 'protective factors' which operate primarily during the childhood and adolescent phases of development (Warner et al, 1971; Werner \& Smith, 1977, 1982; Werner, 1985).

Children with difficult temperaments in infancy can progress, in certain circumstances, to conduct disorder in late childhood (Reid \& Patterson, 1991; Reid,
1993; Campbell, 1995; Coie, 1996; Nagin \& Tremblay, 2001). These childhood syndromes, which increase the risk of progress to an adverse outcome in the next phase, are more likely in the presence of risk factors such as poor family environment, pre- and perinatal difficulties and genetic loading. Developmental research suggests that the presence of more than one risk factor further increases the chances of progression to the next phase but can be balanced by protective factors, for example having a positive social orientation, receiving positive attention during the first year of life, good parent-child relationship, the presence of additional carers besides the mother and structure and rules in the household. These protective factors can overcome the negative effects of risk factors to reduce the chances of progression to the next stage. Children who become delinquent in late childhood and adolescence are thought to have experienced fewer protective factors and form a subgroup demonstrating escalation of their behavioural disorder. Their lack of protective factors may be further compounded by experiences of physical and sexual abuse, family disruption and criminal role models in the family, together with negative influences from other adolescents in their neighbourhood and at school. A small subgroup of individuals may demonstrate psychosexual maladjustment during adolescence. Features of borderline personality disorder may first emerge during this stage, with mood and identity disturbance and incidents of self-harm.

By early adulthood, most individuals drop out of this process and desist from criminal behaviour, settling into relationships and steady employment (Blumstein \& Cohen, 1979). However, a subgroup persists, with the appearance of more serious offending, including violence, and associated substance misuse (West \& Farrington, 1977; Petersilia et al, 1978; Gibbs \& Shelly, 1982; Walters, 1990). By

Table 2 Longitudinal (developmental) conceptual framework for high-risk offenders with personality disorder

\begin{tabular}{|c|c|c|}
\hline Stage & Age & Risk factors \\
\hline \multirow[t]{6}{*}{ A } & Childhood & \\
\hline & Temperament & Genetic \\
\hline & Oppositional defiant disorder & Prenatal, perinatal \\
\hline & Attention-deficit hyperactivity & Family environment \\
\hline & disorder & CNS integrity, IQ \\
\hline & Conduct disorder & Poverty, housing \\
\hline \multirow[t]{6}{*}{ B } & Late childhood/adolescence & \\
\hline & Escalating delinquency & Few protective factors \\
\hline & Peer-group problems & Physical/sexual abuse \\
\hline & Emerging borderline features (mood and & Family disruption/criminality \\
\hline & behavioural disturbance) & Neighbourhood/peer/school influences \\
\hline & Psychosexual maladjustment & \\
\hline \multirow[t]{8}{*}{$\mathrm{C}$} & Early adulthood & \\
\hline & Persisting criminality & Pattern set by earlier factors, maintained by: \\
\hline & Criminal lifestyle/versatility & criminal subculture \\
\hline & Substance misuse & imprisonment \\
\hline & Poor work record & social isolation \\
\hline & Relationship difficulties & anti-establishment attitudes \\
\hline & Sexual deviations & lack of alternatives and skills \\
\hline & Hierarchical appearance of Axis I disorders & \\
\hline \multirow[t]{6}{*}{ D } & Mid-life & \\
\hline & Career criminality & \\
\hline & Psychopathy (high PCL-R score) & \\
\hline & Multiple Axis I disorders & \\
\hline & Repetitive, pervasive antisocial behaviour & \\
\hline & Institutionalisation in secure facilities & \\
\hline
\end{tabular}

CNS, central nervous system; PCL-R, Psychopathy Check-List - Revised. 
this phase, sexual maladjustment in adolescence can develop into paraphilias. In a further subgroup, episodes of severe mental disorder appear (Coid, 1992). These patterns, promoted by earlier risk factors, are now maintained by additional factors such as being part of a criminal subculture, periods of imprisonment, and lack of skills and alternatives to promote a more positive lifestyle.

By their late-20s third and early 30s, most of these individuals present with antisocial personality disorder, but within a spectrum of severity of additional psychopathology. The most severe cases include career criminals, individuals with psychopathy, and multiple Axis II disorders including substance misuse. Escalation and repetitive and pervasive antisocial behaviour lead to prolonged periods of institutionalisation in secure facilities, primarily prison.

\section{Strategies for intervention and prevention}

Prevention programmes need conceptual frameworks to develop interventions and choose the most effective policy. Few intervention strategies are currently available for personality disorder; most are tertiary referral services in secure institutions for individuals at stages $\mathrm{C}$ or D (Table 2). However, a public health approach using Table 2 would suggest early interventions based on this logical sequence of abnormal personality development, having identified the factors determining progression towards the later stages. Although it can be justifiably argued that division into four stages is artificial, this framework facilitates interventions based on theoretical countermeasures. For example, longitudinal research demonstrates that delinquency is common in adolescence but that most individuals drop out early in their 20s. Once individuals have established a criminal lifestyle in their mid- or late-20s, there is unlikely to be further attrition until their 30s or 40s (Hirschi \& Gottfredson, 1983; Walters, 1990). This suggests that intervention strategies should be targeted at earlier life phases during which these individuals are more susceptible to change. For example, conduct disorder is identified as a high-risk precursor of antisocial personality disorder. It is known to affect 4-10\% of children in the UK (Rutter et al, 1975; Kazdin, 1987; Institute of Medicine, 1989; Meltzer et al, 2000) and is associated with attention-deficit hyperactivity disorder. Of this group, $40 \%$ have serious adult psychosocial disturbances, including substance misuse, major mental disorder, higher risk of mortality, and antisocial personality disorder (Robins, 1970; Farrington, 1995; Rutter et al, 1998).

Primary prevention strategies might include:

(a) a targeted approach to those identified as at high risk of developing adult antisocial personality disorder;

(b) increasing the rate of drop out of those presenting with conduct disorder;

(c) prevention of inter-generational transmission within high-risk families;

(d) prevention of the development of conduct disorder by attempting to intervene at an even earlier stage (Coid, 2003). Programmes have been developed to intervene during pregnancy, infancy and the preschool years (Tremblay \& Japel, 2003) through families (specifically directed at parenting) (Utting, 2003) and in schools (Hawkins \& Herrenkohl, 2002).

\section{Setting priorities and policy formulation}

Rose (1992) argues that the public and politicians are highly ambivalent towards experts and advisors, who can confuse their technical authority with the right to decide what is best. Guyer (1998) argues that policy-making is a complex political process that goes well beyond professional expertise alone. It is important to recognise the realities and opportunities of policymaking which require a knowledge base, political will and social strategies. A knowledge base requires information on the size of the problem, its costs and consequences, the extent to which risk factors are causative, and how successful an intervention programme is likely to be. This will require the advice of experts. Political will refers to the willingness of policy-makers to address the problem, which may not be a factor over which experts have much influence. Social strategies are broad methods used by society to solve problems, and may include legislation and regulations to restrict certain behaviours, development of service programmes, provision of funds, etc. Rose recommends a more cautious approach when advising policy-makers. By recognising the roles and positions of the various stakeholders in making policy, experts can give policy-makers the opportunity to consider the full range of strategies that are possible and can explain the consequences to them of each strategy.

When advising policy-makers, it is important to identify the negative cost of not intervening, and to identify policies that have a direct and positive benefit for one section of the community although causing significant public health problems for another. This approach fits with Rose's 'population' approach to preventive intervention and can be highly relevant to interventions for personality disorder and offending behaviour. This is exemplified by the severe deterioration observed within the built environment in certain US urban centres during the 1980s. Continuing deterioration of these environments led to rapid escalation of homelessness, including people with mental illnesses; epidemics of health care problems, most significantly AIDS, tuberculosis and low birth-weight babies (which local underfunded hospitals were unable to sustain); epidemics of substance misuse; and accompanying epidemics of crime and violence affecting primarily ethnic minority populations (Wallace, 1988; Wallace et al, 1992, 1995). An active process had taken place whereby initial scatterings of abandoned structures were followed by intensification and later consolidation as these areas became the focus of vandalism and arson. Fire services within these areas were unable to meet demand, having been downsized as a result of municipal policies to reduce costs and, in some cases, political policy to reduce taxation. Resulting destruction of the environment led to a major population shift to adjacent neighbourhoods, subsequent overcrowding in these new areas and perpetuation of the problem.

Within these deteriorating physical environments, an increasing range of social and health problems progressively emerged. Wallace and colleagues argue that contagious urban decay, rapid loss of housing and population shift had dramatic effects, increasing levels of substance misuse and risk of violent death. Social networks essential for socialisation and control of deviant behaviour and for health maintenance in the population had been dismantled. These problems coincided with progressive supplementation of heroin misuse within these communities by crack cocaine, together with the appearance of AIDS. The effects on children in these environments, many of which constituted 
the known risk factors for conduct disorder, included frequent moves of home, moves to new schools and sometimes failing schools, breakdown of social cohesion as social and family networks disintegrated, loss of parental figures and lack of adequate supervision from adults. This intensified the risk of problem behaviours, including delinquency, gang involvement and recourse to the underground criminal economy.

In such dramatic circumstances, public health professionals and epidemiologists should demonstrate the risks of not maintaining an adequate infrastructure to support population density, the need for programmes of community organisational improvement, provision of adequate housing and economic restitution. However, the need to fund these programmes requires understanding that the economic burden may ultimately fall on taxpayers elsewhere, who may have different cultural expectations and may even be primarily from different ethnic groups. However, Wallace \& Wallace (1997) argue that there is a false assumption in the policies which created these conditions in the first place, and subsequent false assumptions that these problems could be largely confined to the inner-city communities and kept separate from the suburbs and areas where affluent people live and where political power currently lies.

\section{Implementation and evaluation of interventions}

Implementation is defined as the process whereby policy decisions are translated into programmatic activity. Evaluation is the process of measuring the success with which programmes reach their stated objectives (Guyer, 1998). The expansion of new services for individuals with personality disorder following policy decisions in England and Wales requires future evaluation. These include the decision by the Department of Health to expand therapeutic community in-patient services based on the model developed at the Henderson Hospital, and the programme to take forward the Government's proposals on managing dangerous people with severe personality disorder (DSPD).

The latter development exemplifies in part the successful operation of the administrative activities that Guyer describes as essential for programme implementation. These include effective communication concerning all aspects of the programme to all levels of personnel involved in programme delivery, development of procedures and administration to ensure effectiveness, allocation of financial resources and development of monitoring and data systems for evaluation. Despite severe criticisms of the programme on ethical grounds (Eastman, 1999; Mullen, 1999; Gunn, 2000), the Government effectively ignored these and implemented its programme by initially circulating a consultation document (Home Office \& Department of Health, 1999). This was followed by a Home Affairs Committee report which supported the proposals. A Home Office project team was subsequently appointed with the initial task of establishing pilot projects across the prison service and National Health Service (NHS) secure hospital estate to develop and evaluate the assessment process, appropriate treatments and other therapeutic interventions. This has recently been supported by proposals for new mental health legislation (Department of Health \& Home Office, 2000). However, a less than active involvement in the operation of the programme was shown by the Department of Health during the same period. The Government relied primarily on the use of health care resources to deliver a policy of public protection from high-risk offenders driven by the Home Office, which had a key responsibility for this policy but not for development of health care provision. Thus, the stage has not been reached where evaluation as described by Guyer can be carried out. Problems have been compounded in implementation by continuing opposition from the Royal College of Psychiatrists (Royal College of Psychiatrists, 2001).

The stated objectives of the proposals on DSPD to be evaluated in the future are:

(a) to ensure that dangerous people with severe personality disorder are kept in detention for as long as they pose a risk to others;

(b) to provide high-quality services to enable them to deal with the consequences of their disorder, reduce their risk to others and so work towards successful reintegration into the community.

These objectives, narrowly defined, are relatively simple to evaluate and lead to a series of apparently straightforward and testable measures of the effectiveness of the new services.

(a) How effective are the new assessment processes in identifying individuals with severe personality disorder who pose a risk to the public?

(b) How effective are they in identifying when those individuals no longer pose a risk?

(c) How effective is treatment within the new services in reducing risk and promoting reintegration into the community?

However, re-examination reveals that these questions are highly complex, with many associated implications. For example, has the problem been adequately defined for future case identification? Defining personality disorder is already problematic. Certain constructs include factors indicative of risks towards others but without an inherent measure of the severity of these risks. Furthermore, what is the true size of the problem and, consequently, the level of provision required for the programme to be successful? Before measures of prevalence of personality disorder in the population and associations with high-risk behaviour are carried out, prior agreement is required on the level and/or qualitative nature of the risks that are necessary for inclusion. This will inevitably determine future costs.

Finally, how acceptable is it to detain individuals in these new services on the basis of assessment procedures that inevitably contain some degree of error? Is the process of screening sufficiently accurate to avoid missing a substantial number of individuals who still pose a high risk to the public? The latter problem could ultimately bring the new programme (and the professionals who must deliver it) into disrepute with the public and politicians. A public health approach to the problem of personality disorder indicates that evaluation of whether new policies are successfully implemented includes not only their impact on the original stated objectives but also the refining of these objectives.

\section{DISCUSSION}

Although a significant proportion of the population has personality disorder which places considerable burden on a range of agencies, this has not been accurately quantified. The epidemiology of personality 
disorder is still hampered by poor case definition, largely confined to figures of prevalence, and is only beginning to reveal aetiological risk factors. Personality disorders are highly comorbid with each other and with Axis I clinical syndromes over the lifetime, thereby challenging current diagnostic constructs. Emerging knowledge of longitudinal development, and preliminary findings from studies of aetiology, question current concepts of personality disorder, and the fluctuating course of certain conditions does not correspond with the official definition. Current diagnostic classifications are therefore temporary and a broad approach should be taken to case definition.

The few specialist services for patients with personality disorder operate mainly at the tertiary referral level, often in conditions of security. Official policy in England and Wales dictates that these individuals should be treated in conventional psychiatric services. But these currently prioritise patients with severe mental illness. The public health problem-solving paradigm indicates a broader approach to the problem of personality disorder and the need for research into prevention. New policy decisions have raised the profile of personality disorder within the health services of England and Wales. However, it will be necessary to adopt a different approach when advising policy-makers, whose priorities may not coincide with those of clinicians and experts in the field. The paradigm may also be useful in providing policy-makers with the necessary advice on the likelihood of success of their policies and for evaluating the effectiveness of new services.

\section{APPENDIX}

\section{Questions for the future epidemiological study of personality disorder}

(a) What are the aetiological risk factors for personality disorder? Which are most important?

(b) What are the associated factors leading to disability and mortality?

(c) Which disorders of personality lead to the heaviest burden of care?

(d) Which sections of the population have the greatest risk for personality disorder and for experiencing causal factors?

(e) How effective are health programmes, services and interventions in reducing the prevalence of these conditions, their associated morbidity and burden of care?

\section{REFERENCES}

American Psychiatric Association (1994) Diagnostic and Statistical Manual of Mental Disorders (4th edn) (DSM-IV). Washington, DC: APA.

Baron, M., Gruen, R., Rainer, J. D., et al (1985) A family study of schizophrenic and normal control probands: implications for the spectrum concept of schizophrenia. American Journal of Psychiatry, I42, 447-455.

Blumstein, A. \& Cohen, J. (1979) Estimation of individual crime rates from arrest records. Journal of Criminal Law and Criminology, 70, 56I-585.

Brownson, R. C. (1998) Epidemiology: the foundation of public health. In Applied Epidemiology: Theory to Practice (eds R. C. Brownson \& D. B. Petitti). New York: Oxford University Press.

Campbell, S. B. (1995) Behaviour problems in preschool children: a review of recent research. Journal of Child Psychology and Psychiatry, 36, I13-149.

Clark, L. A., Livesley, W. J. \& Morey, L. (1997) Personality disorder assessment: the challenge of construct validity. Journal of Personality Disorders, II, 205-231.

Coid, J.W. (1992) DSM-III diagnosis in criminal psychopaths: a way forward. Criminal Behaviour and Mental Health, 2, 78-89.

- (1993) An affective syndrome in psychopaths with borderline personality disorder? British Journal of Psychiatry, 162, 64I-650.

— (1999) Aetiological risk factors for personality disorders. British Journal of Psychiatry, 174, 530-538.

- (2003) Formulating strategies for the primary prevention of adult antisocial behaviour: "high risk" or "population" strategies? In Early Prevention of Adult Antisocial Behaviour (eds D. P. Farrington \& J.W. Coid) pp. 32-78. Cambridge: Cambridge University Press.

Coie, J. (1996) Prevention of violence and antisocial behaviour. In Preventing Childhood Disorders, Substance Abuse and Delinquency (eds R. DeV. Peters \& R. J. McMahon), pp. 1-18. New York: Sage.

Department of Health \& Home Office (2000) Reforming the Mental Health Act. Part II: High Risk Patients (Cm 5016-II). London: Stationery Office.

Dolan, B. \& Coid, J. (1993) Psychopathic and Antisocial Personality Disorders. Treatment and Research Issues. London: Gaskell.

Eastman, N. (1999) Public health psychiatry or crime prevention? BMJ, 318, 549-55I.

Farrington, D. P. (1995) The Twelfth Jack Tizard memorial Lecture. The development of offending and antisocial behaviour from childhood: key findings from the Cambridge Study in Delinquent Development. Journal of Child Psychology and Psychiatry, 36, 929-964.

Gibbs, J. J. \& Shelly, P. L. (1982) Life in the fast lane: a retrospective view of commercial thieves. Journal of Research in Crime and Delinquency, 19, 299-330.

Gunderson, J. G. \& Phillips, K. A. (199I) A current view of the interface between borderline personality disorder and depression. American Journal of Psychiatry, 148, 967-975.

Gunn, J. (2000) Editorial. A millennium monster is born. Criminal Behaviour and Mental Health, 10, 73-77.

Guyer, B. (1998) Problem-solving in public health. In Epidemiology and Health Services (eds H. K. Armenian \& S. Shapiro), pp. 15-26. New York: Oxford University Press.
Hawkins, J. D. \& Herrenkohl, T. I. (2002) Prevention in the school years. In Early Prevention of Adult Antisocia Behaviour (eds D. P. Farrington \& J.W. Coid). Cambridge: Cambridge University Press.

Herbert, J. D., Hope, D. A. \& Bellack, A. S. (1992) Validity of the distinction between generalised social phobia and avoidant personality disorder. Journal of Abnormal Psychology, 10I, 332-339.

Hirschi, T. \& Gottfredson, M. (1983) Age and the explanation of crime. American Journal of Sociology, $\mathbf{8 9}$ 552-584

Holt, C. S., Heimberg, R. A. \& Hope, D. A. (1992) Avoidant personality disorder and the generalized subtype of social phobia. Journal of Abnormal Psychology, 101, 318-325.

Home Office \& Department of Health (1999) Managing Dangerous People with Severe Personality Disorder. Proposals for Policy Development. London: Department of Health.

Institute of Medicine (1989) Research on Children and Adolescents with Mental, Behavioural and Development Disorders. Washington, DC: National Academic Press.

Jenkins, R. (200I) Making psychiatric epidemiology useful: the contribution of epidemiology to government policy. Acta Psychiatrica Scandinavica, 102, 2-14.

Kazdin, A. E. (1987) Treatment of antisocial behaviour in children: current status and future directions. Psychological Bulletin, 102, 187-203.

Kernberg, O. (1975) Borderline Conditions and Pathological Narcissism. New York: Jason Aronson.

- (1984) Severe personality disorders. In Psychotherapeutic Strategies. New Haven, CT: Yale University Press.

Kohut, H. (197I) The Analysis of the Self. New York: International University Press.

Last, J. M. (1995) A Dictionary of Epidemiology (3rd edn). New York: Oxford University Press.

Loranger, A.W. (1992) Are current self-report and interview measures adequate for epidemiological studies of personality disorders? Journal of Personality Disorders, 6, 313-325.

Lyons, M. J. (1995) Epidemiology of personality disorders. In Textbook in Psychiatric Epidemiology (eds M. T. Tsuang, M. Tohen \& G. P. Zahner), pp. 407-436. New York: Wiley-Liss.

McGlashan, T. H. (1986) The Chestnut Lodge Followup Study: long-term outcomes of borderline personalities. Archives of General Psychiatry, 43, 20-30.

Meltzer, H., Gatward, R., Goodman, R., et al (2000) Mental health of Children and Adolescents in Great Britain. London: Stationery Office.

Moran, P. (1999) Antisocial Personality Disorder. An Epidemiological Perspective. London: Gaskell.

Morey, L. C., Gunderson, J. G., Stout, R., et al (1999) Stability of Five-Factor Traits in Personality Disorder. Symposium 63. American Psychiatric Association 1999 Annual Meeting (proceedings abstract 63B). Washington, DC: American Psychiatric Association.

Mullen, P. E. (1999) Dangerous people with severe personality disorder. BMJ, 319, I146-1147.

Nagin, D. S. \& Tremblay, R. E. (200I) Parental and early childhood predictors of persistent physical aggression in boys from kindergarten to high school. Archives of General Psychiatry, 58, 389-394.

Paris, J. (1988) Follow-up studies of borderline personality: a critical review. Journal of Personality Disorders, 2, 189-197. 
_ , Brown, R. \& Nowlis, D. (1987) Long-term follow up of borderline patients in a general hospital. Comprehensive Psychiatry, 28, 530-535.

_, Nowlis, D. \& Brown, R. (1989) Prediction of suicide in borderline personality disorder. Canadian Journal of Psychiatry, 34, 8-9.

Petersilia, J., Greenwood, P. W. \& Lavin, M. (1978) Criminal Careers of Habitual Felons. Washington, DC: US Government Printing Office.

Reich, J. H. \& de Girolamo, G. (1997) Epidemiology of DSM-III personality disorders in the community and in clinical populations. In Assessment and Diagnosis of Personality Disorders (eds A.W. Loranger, A. Janca \& N. Sartorius), pp. 18-42. Cambridge: Cambridge University Press.

Reid, J. B. (1993) Prevention of conduct disorder before and after school entry: relating interventions to developmental findings. Development and Psychopathology, 5, 243-262.

— \& Patterson, G. R. (1991) Early prevention and intervention with conduct problems: a social international model for the integration of research and practice. In Interventions for Achievement and Behaviour Problem (eds G. Stoner, M. R. Shian \& H. M.Walker), pp. 715-739. Silver Spring, MD: The National Association of School Psychologists.

Riso, L. P., Klein, D. N., Anderson, R. C., et al (2000) A family study of outpatients with borderline personality disorder and no history of mood disorder. Journal of Personality Disorder, 14, 208-217.

Robins, L. N. (1970) Follow-up studies of childhood conduct disorder. In Psychiatric Epidemiology (eds E. H. Hare \& J. K. Wing), pp. 29-89. London: Oxford University Press.

Rose, G. (1992) The Strategy of Prevention Medicine. Oxford: Oxford University Press.

Royal College of Psychiatrists (1999) Offenders with Personality Disorder. Council Report CR7I. London: Royal College of Psychiatrists.

Royal College of Psychiatrists' Mental Health Law Sub-Committee (200I) Response to the White Paper Reforming the Mental Health Act. http: // www.rcpsych.ac.uk/college/parliament /responses/wpmhlsc.htm

\section{Rutter, M., Cox, A., Tupling, C., et al (1975)}

Attainment and adjustment in two geographical areas. The prevalence of psychiatric disorder. British journal of Psychiatry, 126, 493-509.

, Giller, H. \& Hagell, A. (1998) Antisocial Behaviour by Young People. Cambridge: Cambridge University Press.

Shea, M. T., Stout, R., Dolan, R., et al (1999) Shortterm Stability of Personality Disorder Diagnoses. Symposium 63. American Psychiatric Association 1999 Annual Meeting (proceedings abstract 63A). Washington, DC: American Psychiatric Association.

Singleton, N., Meltzer, H., Gatward, R., et al (1998) Psychiatric Morbidity Among Prisoners in England and Wales. London: HMSO.

\section{_, Bumpstead, R., O'Brien, M., et al (200I)} Psychiatric Morbidity Among Adults Living in Private Households, 2000. London: Stationery Office.

Stone, M. H. (1990) The Fate of Borderline Patients. New York: Guilford Press.

Terris, M. (1992) The Society for Epidemiologic Research (SER) and the future of epidemiology. American Journal of Epidemiology, 136, 909-915.

\section{CLINICAL IMPLICATIONS}

- The public health problem-solving paradigm promotes alternative conceptual frameworks of abnormal personality development. From these, new treatment interventions may emerge in the future.

- Risk factors which operate at the population level are important in the aetiology of personality disorder and should be monitored by psychiatrists.

- The paradigm may help psychiatrists renegotiate their relationship with policymakers to promote new services.

\section{LIMITATIONS}

Poor case definition of the personality disorders limits epidemiological research.

- The public health approach to problem-solving is not typically associated with personality disorder, and few UK psychiatrists are trained in public health.

- Treatments for personality disorder in the UK are delivered on an ad hoc basis by general services, which must prioritise major mental illness, or in limited tertiary referral settings.

JEREMY COID, FRCPsych, Forensic Psychiatry Research Unit, St Bartholomew's Hospital, London ECIA 7BE, UK

Thacker, S. B. \& Stroup, D. F. (1998) Public health surveillance. In Applied Epidemiology: Theory to Practice (eds R. C. Brownson \& D. B. Petitti), pp. 105-136. New York: Oxford University Press.

Torgersen, S., Kringlen, E. \& Cramer, V. (200I) The prevalence of personality disorders in a community sample. Archives of General Psychiatry, 58, 590-596.

Tremblay, R. E. \& Japel, C. (2003) Prevention during pregnancy, infancy and the preschool years. In Early Prevention of Adult Antisocial Behaviour (eds D. P. Farrington \& J.W. Coid), pp. 205-242. Cambridge: Cambridge University Press.

Turner, S. M., Biedel, D. C. \& Townsley, R. M. (1993) Social phobia: a comparison of specific and generalized subtypes and avoidant personality disorder. Journal of Abnormal Psychology, I0I, 326-331.

Utting, D. (2003) Prevention through family and parenting programmes. In Early Prevention of Adult Antisocial Behaviour (eds D. P. Farrington \& J.W. Coid), pp. 243-264. Cambridge: Cambridge University Press.

Wallace, R. (1988) A synergism of plagues: 'planned shrinkage'. Contagious housing destruction and AIDS in the Bronx. Environmental Research, 47, I-33.

_ \& Wallace, D. (1997) Socioeconomic determinants of health: community marginalisation and the diffusion of disease and disorder in the United States. BMJ, 314 |34|-1345.

_, Fullilove, M.T. \& Wallace, D. (1992) Family systems and deurbanization: implications for substance abuse In Substance Abuse. A Comprehensive Textbook (eds J. Cowinson, R. Ruiz \& R. Millman), pp. 944-955. Baltimore, MD: Williams \& Wilkins.

_ ,Wallace, D., Andrews, M., et al (1995) The spatiotemporal dynamics of AIDS and TB in the New
York metropolitan region from a sociodemographic perspective: understanding the linkages of central city and suburbs. Environment and Planning, 27, 1085-1108.

Walters, G. D. (1990) The Criminal Lifestyle. Patterns of Serious Criminal Conduct. Newbury Park, CA: Sage.

Werner, E. E. (1985) Stress and protective factors in children's lives. In Longitudinal Studies in Child Psychology and Psychiatry (ed. A. R. Nicol). Chichester: John Wiley \& Sons.

_ \& Smith, R. S. (1977) Kauai's Children Come of Age. Honolulu, HI: University of Hawaii Press.

_ \& _ (1982) Vulnerable but Invincible: A Longitudinal Study of Resilient Children and Youth. New York: McGraw Hill.

,Bierman, J. M. \& French, E. E. (197I) The Children of Kauai: A Longitudinal Study from the Perinatal Period to Age Ten. Honolulu, HI: University of Hawaii Press.

West, D. \& Farrington, D. P. (1977) The Delinquent Way of Life. Third Report of the Cambridge Study in Delinquent Development. London: Heinemann.

Wing, L. (198I) Asperger's syndrome: a clinical account. Psychological Medicine, II, II5-129.

Woolff, S. \& Chick, J. (1980) Schizoid personality in childhood: a controlled follow-up study. Psychological Medicine, 10, 85-100.

World Health Organization (1992) Tenth Revision of the International Classification of Diseases and Related Health Problems (ICD-I0). Geneva: WHO.

Zimmerman, M. (1994) Diagnosing personality disorders. A review of issues and research methods. Archives of General Psychiatry, 5I, 225-245. 